\title{
resenhas
}

DOI: 10.11606/issn.2318-8855.v6i6p337-345

\section{Um Brasil Em Movimento: A marcha para o oeste ${ }^{1}$}

Thays Fregolent de Almeida*

Elizabeth Cancelli, professora livre docente do Departamento de História na Universidade de São Paulo e pesquisadora no Programa de História Social, possui vasto trabalho na área de História do Brasil República, tendo realizado mestrado e doutorado com temas dentro do Estado Novo de Getúlio Vargas. É autora dos diversos livros, entre eles, O Mundo da Violência: a polícia na Era Vargas e o livro aqui resenhado O Estado Novo em Marcha para o Oeste, publicado pela Editora CRV em 2017.

A obra em questão é um livro paradidático, destinado a secundaristas e universitários, rompendo com a lógica de uma produção acadêmica exclusivamente voltada para seus pares. Apesar de não constituir uma obra volumosa, cumpre a importante função de suscitar discussões introdutórias sobre o Estado Novo e as diversas faces da Marcha para o Oeste.

A autora, não apenas nesta obra como em outras, é crítica da tradição historiográfica herdada de Boris Fausto, que acabou por aceitar noções e conceitos cunhados pelos próprios varguistas. Para Cancelli o movimento de novembro de 1930 não é uma "Revolução", mas um "Golpe", dando ênfase ao caráter autoritário do Regime de Vargas desde o seu início. A partir dessa dissidência teórico/metodológica, Cancelli se posiciona de maneira crítica, frente ao repertório conceitual e historiográfico tradicionalmente usando para compreender o período que, argumenta a autora, acabou por cunhar uma visão positiva sobre o ditador. Como aponta Jacques Le Goff:

1CANCELLI, Elizabeth. O Estado Novo em Marcha para o Oeste. Editora CRV, 2017.

* Graduação em História em andamento pela Pontifícia Universidade Católica de São Paulo ( PUC-SP). Tem pesquisa de iniciação científica com financiamento CNPq concluída, referente ao período do Estado Novo, permeando a questão indígena e a discussão historiográfica que consolidou a memória pública acerca dos bandeirantes, cujo título é "Expedição Roncador-Xingu (1943-1948): a tensão entre integrar e preservar os indígenas no Brasil Central". 


\section{artigos}

Thays Fregolent de Almeida

A memória, na qual cresce a história, que por sua vez a alimenta, procura salvar o passado para servir ao presente e ao futuro. Devemos trabalhar de forma que a memória coletiva sirva para a libertação e não para a servidão dos homens. (LE GOFF, 2013, p. 347)

Cancelli trabalha, portanto, no sentido de uma desconstrução da memória cunhada pelo próprio regime. Isso se dá através da elucidação do "discurso político" da época utilizado para a ascensão e a manutenção do poder e através da explicitação da articulação presente entre "ação e discurso", donatária das leituras que a autora fez de Hannah Arendt.

Na obra em questão, Elizabeth Cancelli joga luz na face expansionista do Estado Novo, momento no qual o esforço nacional para a interiorização de recursos e contingentes populacionais para o desenvolvimento do interior do Brasil foi mais incisivo. Nesse sentido, a autora explora temas relativos à busca de um caráter nacional, a Marcha para o Oeste e a própria figura de Getúlio Vargas.

A primeira metade da década de 1940 ficou marcada pelo início da Campanha da Marcha para o Oeste, na qual Getúlio Vargas viajaria pelo Centro-Oeste, Norte e Nordeste do Brasil. No ano de 1941 foram criadas inúmeras colônias agrícolas pelo território brasileiro, no ano seguinte criou-se a Coordenação de Mobilização Econômica e em 1943 foram criadas duas importantes instituições: a Expedição Roncador-Xingu e a Fundação Brasil Central. Carregados de um discurso nacionalista, esses esforços, que se deram principalmente por iniciativa do Estado, visavam a reeducação do "homem brasileiro" de forma que ele se identificasse com os desígnios da nação, ou seja, com a busca de seu caráter nacional.

Para os que se encantam com a história brasileira, adentrar o discurso da Marcha para o Oeste, tão brilhantemente criado e articulado pelo Estado Varguista, é também questionar a fácil saída do diagnóstico historiográfico preso às noções de "atraso", "oligarquias", e de Getúlio Vargas como agente da modernização e de proteção ao homem comum brasileiro. (p.10)

A autora, debatendo com a historiografia acadêmica das últimas décadas, traça uma crítica ao Estado varguista ao contestar sua posição como principal agente da modernização e 


\section{artigos}

Um Brasil Em Movimento: A marcha para o oeste

como provedor da população brasileira. É nesse sentido que Cancelli nos convida a descortinar o discurso da Marcha para o Oeste, a mais efetiva materialização dos anseios pelo desenvolvimento do Brasil. Segundo a autora "ela é sim, como poderemos ver, uma espécie de mito. Não propriamente o mito de origem do capitalismo, mas, certamente, o mito de origem da santificação do autoritarismo" (p.10).

A importância da obra se dá no destaque dado a aspectos centrais do discurso de Getúlio Vargas, de forma a questionar profundamente a análise historiográfica que acabou por consagrar o ditador. Da mesma maneira a obra se faz singular por abordar temas mais periféricos da Marcha, afinal a Expedição Roncador-Xingu, seu trabalho mais efetivo, recebeu pouco destaque ao final do livro.

\section{O ESTADO NOVO EM MARCHA}

O lançamento da Marcha para o Oeste no primeiro do ano de 1938 estava em completa sintonia com os mais recentes e graves acontecimentos políticos que haviam abalado o Brasil. No dia 10 de novembro de 1937, o país ouvira, em cadeia de rádio, o grave anúncio de Getúlio Vargas (1882-1954): estava decretado o Estado Novo (1937-1945). (p.13)

O congresso fora dissolvido, as eleições presidenciais previstas para janeiro de 1938 foram anuladas, todos os partidos políticos foram fechados e foi outorgada uma nova constituição (1937). A partir dessa data Vargas passou a governar através de decretos-lei, aumentou a repressão do Estado, a censura e mobilizou o país na sua campanha rumo à integração nacional.

No lançamento da campanha dizia-se ao povo brasileiro que a tradição de um passado estava sendo quebrada: o Brasil, nação do futuro, não poderia mais se dar ao luxo de voltar as costas ao interior brasileiro. (p.11)

Elizabeth Cancelli nota que a Campanha da Marcha e seus trabalhos respondiam a uma política pública de altíssima densidade. O Brasil, liderado pelo Estado, faria a construção da nação. Primeiro com base na geografia - orientando sua expansão nos sentidos das latitudes 


\section{artigos}

Thays Fregolent de Almeida

-, e também com base simbólica - ao resgatar o bandeirante como os pioneiros dessa expansão que continuaria no século XX.

A Marcha foi um dos projetos políticos de maior dimensão criados por Vargas. De acordo com a autora, devido seu grande apelo ideológico, ela pode ser tida como uma espécie de síntese do pensamento varguista. É nela que podemos observar as principais bases ideológicas que atravessaram as estratégias de dominação e construção do Estado. Nesse sentido, a ocupação do interior vinha acompanhada do nacionalismo autoritário, isto é, a figura do líder, uma promessa futurística de sociedade e a construção de um homem novo o ser brasileiro. Realizar a Marcha - ou pelo menos acreditar nela - tornou-se uma empreitada cívica e patriótica, representava fazer parte verdadeiramente da vida pública e da construção da nacionalidade.

A autora problematiza a aceitação de que há uma dicotomia entre discurso e ação, como se um não fizesse parte do outro, o que dificulta a análise histórica e a construção historiográfica. Cancelli se propõe a mostrar que não há separação entre discurso e ação, afinal, o discurso, quando produz sentido, vai sendo incorporado em sua atmosfera até que acaba tendo um efeito prático.

\section{DISCURSO E CONTROLE}

O Estado Novo utilizou todo seu aparato institucional e de controle sobre os meios de comunicação de massa para produzir uma gama de publicações e programas radiofônicos, estimulando o andamento e o sucesso da Marcha para o Oeste. Em 1939 fundou-se o Departamento de Imprensa e Propaganda (DIP), sucessor de várias outras agências de controle de informação criadas pelo Regime desde 1931. Esta foi a arma de maior eficácia da disseminação do discurso varguista. Interessante notar que o mito do pai estadista foi reforçado com as próprias comemorações cívicas promovidas pelo Estado Novo, que eram filmadas pelo DIP e posteriormente projetadas nas salas de cinemas em forma de documentários Brasil a fora. 


\section{artigos}

Um Brasil Em Movimento: A marcha para o oeste

Segundo Cancelli, o cerne da campanha da Marcha era o seu sentido cívico. Dessa maneira, Vargas dava ao Brasil uma nova determinação: a "de buscar a ação vitoriosa da coletividade" para a integração nacional. O ponto fundamental utilizado para unir a população foi o nacionalismo. Francisco Campos e Alberto Torres, dois dos ideólogos mais importantes do Estado Novo, elaboraram uma crítica ao liberalismo, que seria, segundo eles, o gerador da fragmentação brasileira na Primeira República. Suas teses defendiam o nacionalismo como "força aglutinadora de interesses" e como um elemento fundamental para a política de legitimação do Estado. Além disso, era através do nacionalismo que se definiria o papel social do indivíduo: orgânico.

Tentava-se, desta forma, apagar quaisquer vestígios de divisão social, de luta de classes, ou, para irmos mais longe, de espaço público (lugar onde o Homem fala e age), na medida mesmo em que se negava o mundo político, da pluralidade, da diversidade e da possibilidade de conflito. Substituia-se o conceito de sujeito pelo de massa. (...) Este novo homem que surgia, o homem das massas, era agora percebido somente como brasileiro que deveria, antes de mais nada, identificar-se pelo sentimento do nacionalismo. (p.20 e 21)

A partir da atuação do DIP nos jornais, no cinema e no rádio - principal formador da consciência cívica e da opinião pública - foi fabricada a imagem de uma grande comunidade nacional. Portanto, a legitimação do Estado se deu através da propaganda e de um inédito aparato repressivo responsável por garantir 'o bem-estar social'.

Como mostra Cancelli, Getúlio Vargas representava mais do que a figura de um presidente. Desde sua posse houve um grande esforço de construir uma entidade mitológica, ideia reforçada nas manifestações populares em homenagem ao Presidente. Era o chefe da nação o principal incentivador da Marcha para o Oeste que 'orientava a caminhada dos novos bandeirantes', quem assegurava à sociedade identidade e unidade. Por fim, nota Cancelli, o mito do pai da nação, do gênio estadista caminhava lado a lado com um grande outro mito: o do nacionalismo.

Apresentado como o homem que possuía a identidade do ser brasileiro, ele servirá de exemplo, de princípio condutor, para o homem comum, carente, 


\section{artigos}

Thays Fregolent de Almeida

como homem de massas, de rumo e de identidade. O gênio encaminhará a sociedade rumo ao sonho da nação do avenir. (p. 33)

A estratégia estadonovista de realizar o esforço de interiorização do homem e dos recursos estava assentada em três pontos segundo Cancelli:

1. o seu caráter de conquista, que imprimia a noção de uma sociedade sempre a ser construída.

2. a preocupação em construir um novo tipo de homem, o "Homem Novo", como o estado chamava este sujeito das massas a ser moldado.

3. a interiorização do flagelo que ameaçava a ordem urbana.

Em todos os pontos, a regeneração pelo trabalho era uma tônica constante. Portanto, o enobrecimento do homem - no sentido de construir uma "raça brasileira" mais forte, saudável e capaz - estava baseada no discurso de glorificação do trabalho. Discurso esse presente na própria Constituição de 1937 devidamente trazido pela autora: art. 136 da Constituição: o "trabalho é um dever social".

Construía-se uma nova disciplina com o intuito de forjar a criação de uma nova identidade nacional. A proposta estadonovista, portanto, se dava pelo que Vargas chamava de "triangulado do progresso", que seria sanear, educar e povoar. Materializando esses três pilares temos a ampliação das organizações estatais de saúde, uma nova educação cívica que reforçava o culto das tradições nacionais e a campanha da Marcha.

\section{POVOAR A NAÇÃO: A MARCHA PARA O OESTE}

Era o próprio Getúlio quem, naqueles tempos de Segunda Guerra Mundial, quando a disputa por territórios e zonas de influência marcavam drasticamente o mundo, dizia "que nenhum brasileiro admitiria a hipótese de ser cedido um palmo desta terra que é sangue e carne de seu corpo". (p.46)

A autora, de modo muito apropriado, resgata o contexto internacional. Pois, a partir da perspectiva dos acontecimentos exteriores, a imensidão do Brasil, por muito tempo motivo 


\section{artigos}

Um Brasil Em Movimento: A marcha para o oeste

de orgulho, tornou-se motivo de preocupação com a suposta cobiça gerada pela Segunda Guerra Mundial. O Estado Novo politizou o debate acerca da ocupação do imenso e esparsamente povoado território, para deste modo sustentar o sentido da colonização ligado ao dever que implicava a brasilidade: 'ocupar as áreas a fim de preveni-las contra o invasor'.

\footnotetext{
A empreitada visava a combater o conjunto de quatro inimigos do Estado: 1) todos os países que ambicionavam fatias do território brasileiro, especialmente os países limítrofes com o Brasil nas regiões de escassa população; 2) os "judeus-errantes", homens ideologicamente condenáveis; 3) a cobiça do capital estrangeiro; 4) a apatia e a pobreza. (p.48)
}

Refletindo sobre os perigos já apontados, a "apatia e a pobreza do homem do campo" constituíam-se em um importante inimigo interno a ser atacado. Sendo um homem socialmente desintegrado, era visto como despreparado para contribuir no sentido do fortalecimento da nação. Desse modo, cabe afirmar que a Marcha para o Oeste recebeu a conotação de um empreendimento de segurança nacional e, portanto, de aparente urgência. Foi na palestra sobre a "Nacionalização e Colonização das Fronteiras", que o general Francisco José Pinto afirmou que: “(...) a Comissão de Estudos criada para atacar o problema possuía vários projetos, entre eles o de criação de territórios federais e de colônias militares na faixa das Fronteiras, o que seria consolidado em 1943 (...)" (p.52)

Interessante notar que Cancelli aborda aspectos militares da ocupação, principalmente no que diz respeito às colônias na região das fronteiras. Essas terras supostamente doadas pelo governo vinham junto com uma promessa de uma "terra prometida". Dessa maneira, "o caráter dado à hinterlandia, como terra prometida, preenchia um vazio de expectativas de um povo que sofria a diáspora provocada pela miséria e pela seca" (p.52). A autora traz a constatação da Fundação Brasil Central na qual verifica-se que o homem que deixava as grandes cidades 'era um exército de flagelados', em sua maioria de origem nordestina, ou provindos do interior de Minas Gerais e da Bahia, sem meios de adquirir terras.

“(...) sem a possibilidade de simplesmente ocupar as terras, como foi feito na expansão da fronteira norte-americana em sua marcha para o oeste, só seria 


\section{artigos}

Thays Fregolent de Almeida

viável a ocupação do hinterland se o Estado proporcionasse o acesso ao solo através da concessão (...) Uma realidade agravada pela dependência de favores políticos no que diz respeito, especialmente, à caótica situação em que se encontravam os processos de requisição legal dos terrenos. A saída encontrada pelo Estado Novo é a maneira peculiar como tratou a questão da colonização da Marcha para o Oeste. (p. 54 e 58)

Assim, para garantir que a ocupação se realizasse deveria ser reforçada a imagem de um imenso local desocupado. É nesse sentido, que a autora apresenta uma série de tabelas onde se apreende que os estados de Goiás e Mato Grosso, já na década de 40, tinham altos índices de concentração fundiária. Segundo o Conselho de Segurança Nacional, não chegava a $1 \%$ da população os que possuíam terra. Parte do Estado do Mato Grosso (assim como outros estados da região Norte) apresentava grande quantidade de terras devolutas, no entanto, distantes do mercado, impossibilitando a ocupação e incorporação econômica.

A intenção sempre repetida pelo Estado Novo era a de fazer com que as fronteiras políticas coincidissem com as fronteiras econômicas: um pressuposto de representação da unidade nacional. O símbolo da unidade nacional, da coincidência econômica e política, carregava um dos elementoschave que tudo faria possível: a entrega ao trabalho. (p.53)

A política adotada não se tratava de simplesmente ocupar o espaço, mas de ocupar com o trabalho determinados espaços. Sobre essa questão da colonização foi o Conselho de Segurança Nacional que definiu as várias diretrizes que marcam a legislação estadonovista sobre a questão. Sintetizando, as principais ideias dessa política podem ser apreendidas em quatro fases: social, pela incorporação do indígena e sociedade brasileira e pela fixação do indivíduo ao solo; econômico, pelo desenvolvimento das fronteiras a partir desses elementos de produção; científico, pelo estudo de tais regiões; e militar, 'pela ocupação imperiosa de todos esses setores enriquecidos pela ação devidamente protegida'. Ou seja, foi na fixação do homem à terra que o projeto do Conselho de Segurança Nacional encontrou a possibilidade de qualificar a população para o trabalho e também estimular a consciência de ser brasileiro.

O ano de 1943 se fez importante para a Campanha da Marcha para o Oeste através da criação Expedição Roncador-Xingu pelo governo federal. O objetivo era o adentramento ao 


\section{artigos}

Um Brasil Em Movimento: A marcha para o oeste

Brasil Central, a fim de de ocupar e colonizar as vastas áreas do Araguaia e Xingu até a Amazônia e o Pará. Nesse mesmo ano, em Xavantina - primeiro posto-base da expedição - foi sediada a Fundação Brasil Central. Seu chefe, João Alberto, também exercia a presidência da Coordenação de Mobilização Econômica, criada em 1942, após a entrada do Brasil na Guerra.

Uma última instituição, criada nesse período, a ser citada é a Comissão Administrativa de Encaminhamento de Trabalhadores para a Amazônia, responsável por fixar na região cerca de 22 mil 'soldados da borracha' de 1943 a 1945. O plano de trabalho divulgado previa o assentamento e amparo desses trabalhadores, no entanto 'eram arregimentados ao deusdará'. Mas, o que nos interessa é que até 1945, ano da queda de Getúlio Vargas, o Estado Novo continuou fazendo sua política de conquista do Oeste.

\section{CONSIDERAÇÕES FINAIS}

A partir da pesquisa de Elizabeth Cancelli, é possível compreender que no cerne das grandes estratégias políticas elaboradas após 1930, a Marcha para o Oeste representa o primeiro grande esforço moderno de interiorização de recursos e contingentes populacionais para as regiões mais longínquas do país, entendidas como Centro-oeste e a Amazônia.

A obra da autora é importante para compreender não especificamente as ações e as vitórias e fracassos da Marcha, mas sim o discurso e a atmosfera que a propagou. Ademais a autora também mostra no decorrer do livro que houve diversas ramificações da grande Campanha da Marcha para o Oeste, e que esta encerra em si diversos aspectos. E mais, que esse grande esforço varguista sobreviveu ao seu próprio período, sendo retomada nas campanhas de interiorização dos governos de Juscelino Kubitschek e mesmo dos governos militares pós-1964. Como bem coloca a autora, a Marcha para o Oeste acabou por "ratificar uma grande mítica nacional: a de que ainda não somos, mas ainda seremos" (p.72).

Por fim, a autora nos deixa a seguinte reflexão: acreditar que o genuíno desígnio da brasilidade era o de construir um país novo era também acreditar que seu destino construído em cima da busca de uma unicidade era o de ser um 'país do futuro'. 